\title{
METALINGUISTIC NEGATION AND ECHOIC USE 1
}

\author{
Robyn Carston \\ University College London
}

\begin{abstract}
Summary:
The metalinguistic use of 'not' has been brought to prominence by the work of Laurence Horn, who characterizes it as a marked, non-truthfunctional use of negation, not reducible to the standard truth-functional operator. Discussion of the phenomenon so far has focused on those cases which tend to temporarily garden-path the hearer and achieve interesting rhetorical effects in the process. The notorious 'presupposition'-cancelling negation cases have been included here. I argue that this emphasis has diverted attention from the essential property of these examples which is that (at least some of the material falling within the scope of the negation is echoically used, in the sense of Sperber and Wilson (1986). Once this is recognized the picture opens up considerably and it becomes evident that none of the standardly cited properties, including garden-pathing, is essential. Furthermore, there seems to be no need to postulate any kind of ambiguity in the negation operator itself; rather, the two uses fall out from our perfectly general capacity to use language either to represent states of affairs or to represent other representations, including other utterances.
\end{abstract}

\section{Introduction}

What I hope to achieve in this paper is some rather deeper understanding of the semantic and pragmatic properties of utterances which are said to involve the phenomenon of metalinguistic negation[FN1]. According to Laurence Horn, who has been primarily responsible for drawing our attention to it, this is a special nontruth-functional use of the negation operator, which can be glossed as 'I object to $U$ ' where $U$ is a linguistic utterance. This is to be distinguished from descriptive truth-functional negation which operates over a proposition.

The distinction is illustrated by example (1), with the two possible follow-up clauses given in (a) and (b):

(1) We didn't see the hippopotamuses.

a. We saw the rhinoceroses.

b.We saw the hippopotami.

1 Journal of Pragmatics'in 1996 sayısında yayımlanacak olan bu yazıyı, Dilbilim Araştırmaları 1996'da yayımlamamıza izin verdiği için Robyn Carston'a teşekkür ederiz. 
In the case of (1) with the (a) follow-up clause we have the standard truth-functional negation and the utterance is descriptive of some aspect of the world. The negative statement and the following clause are consistent with one another: there is one set of creatures in the world that we didn't see and there is another, different, set of creatures that we did see. The propositional structure is 'not P; $Q$ '. In the (b) case, on the other hand, such a descriptive understanding would lead to a contradiction, since we would be saying of the very same set of creatures both that we didn't see them and that we did see them, i.e 'not P; P'. But (1) followed by (b) is not, of course, understood in this way. It is taken to be communicating an objection to some property of the representation falling within the scope of the negation, some property other than its truth-conditional semantic content, in this case the particular manifestation of the plural morphology of the word 'hippopotamus'.

A range of cases is given in (2), representative of the examples standardly cited in the literature (see Horn 1985, 1989, Burton-Roberts 1989a, 1989b):

a.We don't eat tom[a:t uz] here, we eat tom[eiD uz].

b.He isn't neurotic OR paranoid; he's both.

c.I haven't DEPRIVED you of my lecture on negation;

I've SPARED you it.

d.She's not my mother; she's my female progenitor.

e.The President of New Zealand ISn't foolish; there IS no President of New Zealand.

This gives some idea of the sorts of properties that might be objected to by this use of negation: the pronunciation of a word in (2a), the insufficient strength of a lexical item used in (2b)[FN2], a non-truth-conditional aspect of the semantics of a word in (2c)[FN3], the stereotypic assumptions or connotations that come with a particular word or phrase in (2d), an existential 'presupposition' carried by a sentence/utterance in (2e). This is summed up by Horn $(1989,363)$ : "[metalinguistic negation is] à device for objecting to a previous utterance on any grounds whatever, including the conventional or conversational implicata it potentially induces, its morphology, its style or register, or its phonetic realization." This statement is quite typical: while 'any grounds whatever' might seem to include truth-conditional content (believing someone's utterance to be false is a good ground for objecting to it), it is always followed up by a list which does not include it. Most people seem to assume that since descriptive negation deals with truth-conditional content, this other kind of negation, used to register an objection, need not and does not. I shall return to this matter in section 5 .

So we have two uses of the negation operator; the question is whether the distinction between them is to be captured pragmatically, or is a semantic matter. 
Horn wrestles with the issue of how to characterize the relationship between these two ways of interpreting a negation; he insists that it does not amount to a semantic ambiguity, an ambiguity within the linguistic system itself, and calls it a pragmatic ambiguity, a 'built-in duality of use', which extends to other linguistic operators such as 'if', 'or' and 'and' (see Horn 1989, 379-382). However, in the absence of any further specification the concept of 'pragmatic ambiguity' is at best hopelessly vague. A number of writers have puzzled over what it might be taken to mean (Burton-Roberts 1989b, Foolen 1991, van der Sandt 1991, Carston forthcoming), without reaching any concrete conclusions.

Horn himself is inconsistent in his discussion, writing of 'an extended metalinguistic use of a basically truth-functional operator' (Horn 1985, 122), followed soon after by reference to 'this special or marked use of negation, irreducible to the ordinary internal truth-functional operator' (Horn 1985, 132). Despite his avowals to the contrary, it seems to me (and to van der Sandt (1991, 333)) that Horn's is essentially a semantic ambiguity position. In fact it involves a two-fold ambiguity. There is an ambiguity in the negation operator itself: the one is the logical, truth-value reversing, negation, the other is a non-truth-functional operator expressing objection. And the further ambiguity lies with the nature of the material falling in the scope of the negation, whether it is a proposition or an utterance. This is unsatisfactory on at least two counts: first, intuitions are violated by the idea that 'not' itself is ambiguous, and second, there is an odd redundancy in this double ambiguity. I hope to dispel the air of mystery that surrounds this issue of the two uses/senses of negation and how they are related to each other, but first let us take a look at some of the features cited as typical of metalinguistic negation.

\section{Properties of metalinguistic negation}

A. Felicitous metalinguistic use standardly involves the 'contradiction' intonation contour (a final rise within the negative clause), followed by a correction clause, and contrastive stress on the offending item and its replacement. See, for instance, Horn $(1989,374)$.

B. The metalinguistic use of negation standardly occurs in rejoinders to utterances of the corresponding affirmative. See, for instance, Horn $(1989,375)$ and BurtonRoberts (1989b, 222).

C. They are garden-path utterances, requiring double processing (pragmatic reanalysis) in order to be correctly understood. 
"... the descriptive use of negation is primary; the non-logical metalinguistic understanding is typically available only on a 'second pass', when the descriptive reading self-destructs." (Horn 1989: 444).

D. Taken literally (i.e. not metalinguistically) the two clauses in each example constitute a logical contradiction. (Burton-Roberts 1989a, 1989b chapter 10).

E. The material falling in the scope of the 'not' is mentioned (metarepresented, quoted, echoic) rather than used. (Burton-Roberts 1989a, 1989b chapter 10).

The last property is, in my view, the only one of the five which is essential to this use of negation. The frequent, though by no means inevitable, presence of the other characteristics is a consequence of the metarepresentational nature of the material in the scope of the negation. This property lends itself to the special rhetorical effects achieved by garden-pathing and reprocessing. At least, this is what I wish to show. I will look now at a number of examples which demonstrate the inessential nature of these other properties.

Consider example (3); the first line is the text on the front of a birthday card, the next two lines are the text inside:

(3) This Birthday Card is NOT from one of your admirers.

It's from TWO of your admirers.

Happy Birthday from both of us.

(Horn 1992)

The idea is, of course, to deliberately mislead the receiver, who first reads the front, into taking it descriptively; then when the card is opened and the message inside is read the descriptive understanding is recognised as mistaken and there is a reanalysis in terms of the metalinguistic use. So, certainly, property $\mathbf{C}$ is realised here, the extra processing effort required giving rise to the extra (mildly humorous) effects as Relevance Theory (Sperber and Wilson 1986, 4.4) would predict. However, the supposedly typical accent pattern is not in evidence; as a written message the contradiction contour cannot be indicated and the stress pattern reflected in the upper case letters does not contrast the offending item 'one' with its replacement 'two'. As Chapman (1993) points out, this clue to the metalinguistic interpretation is deliberately withheld in order to ensure the garden-pathing and reanalysis. Furthermore, there is clearly no utterance to which this one is a rejoinder, and Horn's suggested gloss for metalinguistic use: "I object to the utterance 'this birthday card is from one of your admirers'", is very strained here. In fact, the 
absence of these first two properties is quite typical of those cases which involve an intended garden-path; giving the hearer/reader such clues would only undermine the trick.

While Horn $(1985,1989)$ takes garden-pathing and reanalysis to be merely typical of cases of metalinguistic negation, Burton-Roberts (1989b) seems to see it as essential[FN4]. There is good reason to doubt its inevitability. Consider the examples in (4), where I have made the simple move of reversing the order of the negative clause and the so-called correction clause, so that what the hearer accesses and processes first has changed:

(4) a.Maggie's patriotic AND quixotic; not patriotic OR quixotic. b.I've SPARED you my lecture; I haven't DEPRIVED you of it. c.It's downright HOT out there, it's not WARM.

The correction clause is now (part of) the context in which the negative clause is processed. This shouldn't make any difference to the metalinguistic character of the utterances; a speaker of (4a) is objecting to someone's affirmative utterance that 'Maggie is patriotic or quixotic' just as much as a speaker of the clauses in the other order. Similarly, if the one order makes for a logical contradiction so must the other: if understood descriptively, what a speaker of (4a) would be taken to be communicating would be that Maggie has two properties, F and G, and that she has neither of these properties, F and G. But, and this is the point, there is surely no double processing of the negative utterance here; the metarepresentational nature of 'patriotic OR quixotic' is recognised straight off as such, without a preliminary stage of assuming a descriptive use. The first clause prepares the way for it, making it clear to the hearer that the speaker does not dispute the truth-conditional content that Maggie is patriotic or quixotic, since she has just made the stronger assertion that entails it. The negative clause will be processed on its first pass as a case of metalinguistic use. The same goes for (4b) and (4c).

The second sort of case where metalinguistic negation is recognized on a first pass is when something is explicitly marked as quotational. In written language we have an obvious way of doing this: the use of quotation marks, as in (5):

a.I'm not "his child"; he's my father.

b.You didn't see two "mongeese"; you saw two mongooses.

Surely when these are physically present as they are here, a reader does not first understand the material within the marks descriptively/truth-conditionally and only give up on that when he encounters a contradiction. The same point applies to the quite common practice, among English speakers at least, of accompanying parts of 
a spoken utterance by a paralinguistic gesture of drawing quotation marks in the air. There are other, less determinate, indicators in speech, such as the contradiction contour and the placement of focal stress, which may direct a hearer straight to the metalinguistic interpretation. As we saw above with example (3), when a speaker or writer is intent on garden-pathing a hearer or reader, these clues are likely to be withheld.

Given the highly context-sensitive nature of utterance interpretation it is reasonable to suppose that there is a third sort of case which does not require double processing, the case where a particular context makes the metalinguistic interpretation immediately accessible. In such a case a follow-up correction clause is unnecessary:

(6) [context: A and B have an ongoing disagreement about the correct plural of "mongoose", A advocating "mongeese" and B "mongooses".]

A: We saw two mongeese at the zoo.

B: Now, come on, you didn't see two monGEESE.

In the context given, A might well recognise on a first pass the non-descriptive nature of the utterance with its implicit correction of the plural morphology of 'mongoose'. If their dispute is still sufficiently alive in her mind she may have produced her own utterance as a deliberate provocation and be anticipating B's response.

In the context of a discussion of the double processing typical of cases of metalinguistic negation, Horn (1992) considers various 'devices for triggering reprocessing':

a.You're my favorite person. Not!

b. He's a fine neighbour, I don't think.

While he agrees that garden-pathing is not a necessary attribute of metalinguistic negation, he says "it does seem to be built into these devices: retro-NOT and ironic postposed 'I don't think!'" (Horn, personal communication). I doubt that gardenpathing is inevitable even in such cases. Certainly, they lose their effect if the hearer has already accessed, say, an ironic interpretation before getting to them, as seems fairly likely for a case such as ( $7 b$ ) across quite a range of contexts (the word 'fine' often cues irony). The utterance would simply have a rather lame, heavyhanded feel to it, explainable in relevance-theoretic terms as putting the hearer to some pointless processing effort, hence as failing to achieve optimal relevance. Garden-pathing and reprocessing is never inevitable, just more likely with certain linguistic devices in certain contexts. 
Most of the cases of metalinguistic negation presented in the literature are abstracted from contextual specifics and, as they are in written form, they have few of the typical accentuation features which function as clues towards a metalinguistic reading, so we cannot make a blanket generalization about how they are processed. In this regard, metalinguistic negatives are no different from metalinguistic affirmatives:
a.You may have seen some mongeese but as far as I'm concerned I saw some mongooses.
b.In America they eat tom[eiD uz]; here we eat tom[a:t uz].

These, too, may first be processed as descriptive and then, when they 'self-destruct', be reanalyzed as metalinguistic, or they may be recognized immediately as metalinguistic, depending on the hearer/reader's most accessible context.

So metalinguistic use need not be disguised or initially misleading as in some of the earlier cases; it may be plain to see from the beginning. If so, the processing effort it requires and the effects achieved will be rather different from that of the 'double processing' cases. If I am right that the reverse order examples in (4) are recognised as metalinguistic on a first pass, Relevance Theory would predict that, since they require less processing effort than the standard Horn cases, they should give rise to fewer, or at least different, effects. Intuitively, at least, this seems to be correct.

The examples in (4), (5) and (6) show that the understanding of a negation as metalinguistic need not involve garden-pathing, though (4) and (5) ARE logical contradictions when taken descriptively. Burton-Roberts (1989a, 1989b) has emphasised this property, motivated by his commitment to a presuppositional semantics for natural language. Before considering the presupposition-denying cases let us consider whether metalinguistic cases are generally descriptive contradictions.

(9) a.He doesn't need FOUR MATS; he needs MORE FATS.

b.X: You seem amused by my problem.

Y: I'm not Amused by it; I'm BEmused by it.

c.I didn't put him up; I put up with him.

These examples are obviously quite consistent when taken descriptively and I do not see any reason to suppose they wouldn't be interpreted as objections to some property of a previous utterance, hence as metalinguistic. In all three the focus of the objection is a property of linguistic form although it also happens to make a 
difference to truth-conditional content. However, opinion is divided at this point. Kempson $(1986,84)$ and Foolen $(1991,222)$ assume that these are (at least potentially) cases of metalinguistic use and Horn $(1989,403 ; 1990,498)$ himself gives similar non-contradictory examples of metalinguistic negation. BurtonRoberts (1989a, 1989b), on the other hand, excludes these from being cases of metalinguistic negation precisely because they are not logical contradictions. His claim is that contradictoriness is the single unifying property of all cases of metalinguistic negation and that it is this that provides the rationale for the pragmatic reanalysis which these cases inevitably, according to him, undergo.

However, it is not entirely clear what the contradictoriness claim amounts to when we consider a further sample of cases standardly cited, by Horn, BurtonRoberts and others, as metalinguistic negations:
a.He didn't eat THREE of the cakes; he ate FOUR.
b. They didn't fall in love and get married; they got married and fell in love. c.semantics: not [P \& Q]; Q \& P
first pass pragmatic processing: not [P \& then Q]; Q \& then $P$

On the most widely accepted (linguistic) semantic analysis of (10a) and (10b) they are indeed semantic contradictions (Horn 1985, Kempson 1986, Carston 1988, Burton-Roberts 1989b). But it is far from obvious that they are contradictions in on-line processing; if much current work in pragmatics is on the right track then these examples standardly involve pragmatic enrichment at the level of the proposition expressed by the utterance (its truth-conditional content). This is demonstrated in (10c) for $(10 b)$ : by the time the hearer reaches the end of the first clause he will have enriched the conjunctive relation to include temporal sequence so that the subsequent processing of the follow-up clause will not result in a contradiction. Similarly, the enrichment of 'three' to 'exactly three' in the left to right processing of $(10 \mathrm{a})$ will ensure that the first pass descriptive interpretation is consistent. This does not entail that these will never be cases of metalinguistic use. In an appropriate context they might well be, but their interpretation as such won't be prompted by the derivation of a contradiction.[FN5]

I shall argue that, in a certain sense, the 'presupposition'-denying cases are the mirror image of these, in that while they are not semantic contradictions, the interpretation made on a first pass does standardly result in a contradiction.

\section{The 'presupposition'-denying cases}

As already mentioned, cases such as those in (11), which involve a follow-up correction clause denying a presupposition carried by the affirmative counterpart of 
the first clause, are standardly included in the lists of metalinguistic negation examples:

(11) a.The President of New Zealand isn't a fool; New Zealand hasn't got a President.

b.I haven't given up smoking; I've never smoked.

c.I don't regret telling her my secrets; I haven't told

her anything.

They certainly feel similar to the other cases: they are most easily contextualized as rejoinders to an utterance of the affirmative, they are most readily uttered with the typical contradiction contour and they have the marked, garden-pathing effects that the other examples in (2) standardly have.

Are they logical contradictions? On Burton-Roberts' account of presupposition as a semantic relation, intrinsic to the linguistic system, they must be. It follows from the definition of semantic presupposition that each of the negative sentences in (11) carries the same presupposition as its affirmative counterpart. Therefore, in each case the follow-up clause contradicts the preceding negative sentence. It is this that prompts the pragmatic reanalysis in terms of a metalinguistic use of the negative element. Burton-Roberts' (1989a, 1989b) analysis for (11a) is given in (12):

semantics: [the $\mathrm{P}$ is not-F]; there is no $\mathrm{P}$.

which is a contradiction

pragmatic reanalysis: not ['the $\mathrm{P}$ is $\mathrm{F}^{\prime}$ ]; there is no $\mathrm{P}$

He argues that a unified account of metalinguistic negation (in terms of logical contradiction) and the semantic account of presupposition need each other. His line of reasoning is as follows:

(a) These 'presupposition'-denying cases are standardly cited as cases of metalinguistic negation (by Horn, and others).

(b) Metalinguistic negations (quite generally) are descriptive (semantic) contradictions (see 2(a-d) and (5)).

(c) It is only in a presuppositional semantics that these 'presupposition'denying cases qualify as semantic contradictions (since, by definition, the negation operator of a presuppositional semantics preserves presuppositions.[FN6]) 
(d) Therefore it is only on a presuppositional semantics that you get a unified account of metalinguistic negation (in terms of semantic contradiction forcing pragmatic reanalysis of the negation as metalinguistic).

(e) Therefore the metalinguistic analysis of 'presupposition'- denying cases requires that presupposition be understood as a property of natural language semantics (as opposed to pragmatics).

First, it is far from obvious that metalinguistic negations are generally logical contradictions, as we saw above. This is mere stipulation on Burton-Roberts' part. Second, there appears to he considerable evidence scattered throughout the literature that the presupposition-denying cases themselves are not logical contradictions (see Kempson 1986, Horn 1990, Seuren 1990, Horn 1992). In addition to that evidence which I will not review here, I would like to point to a sharp distinction between these presupposition-denying cases and the other metalinguistic cases. The very property that led to the standard metalinguistic cases being called 'paradoxical negations' does not seem to extend to the 'presupposition' cases. As Horn (1989, 431-2), following Cormack (1980), points out, these negations seem to be paradoxical because their affirmative counterparts are entailed by their correction clauses; that is, given the schematic representation of these examples as 'Not P; Q', the following seems to be the case: 'Since/if Q, then P':

a.She murdered him; he's still alive.

a'If he's still alive then she didn't murder him.

b.She's not happy; she's ecstatic.

b'If she's eestatic then she's (certainly) happy.

c.I'm not his child; he's my father.

c'If he is my father then I am his child.

d.The President isn't foolish; there is no President.

d'??If there is no President then the President is

foolish.

e.I haven'l given up smoking; I've never smoked.

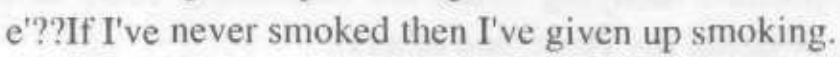

The example in (13a) does not involve the negation operator but is included as a typical semantic contradiction; it is typical in that the second clause entails the negation of the first. The paradoxical negation cases evince the same property in that their follow-up clauses entail the affirmative counterpart of the negative clauses. However, applying the same procedure to the presupposition-denying cases, as in (13d) and (13e), gives nonsense, which is only to be expected since they precisely are not paradoxical/contradictory. 
This, in fact, jeopardizes the entirety of Burton-Roberts' semantic presupposition position. Here, though, the point of immediate interest is that it provides further evidence against the general claim that metalinguistic negations are semantic contradictions. What, then, of the strong intuition that there is some tension, if not contradiction, between the first clause and the second, and that they do, frequently at least, require double processing? The analysis $I$ argue for in Carston (forthcoming) involves an extension of the standard 'Gricean' analysis, long argued for by the anti-presuppositionalists, Wilson, Kempson, Grice, Atlas, Boer \& Lycan.

a.semantics: not [the $\mathrm{P}$ is $\mathrm{F}$ ]; there is no $\mathrm{P}$

(i.e. 'presupposition'-cancelling, wide-scope, uncommitted negation)

b.standard first pass pragmatic processing:

[the $\mathrm{P}$ is not-F]; there is no $\mathrm{P}$

(i.c. pragmatic enrichment/narrowing in order to meet manner/quantity and/or relation maxims (consistency with optimal relevance expectations.))

c.second pass pragmatic processing (reanalysis):

either: not ['the $\mathbf{P}$ is $\mathbf{F}$ '] there is no $\mathbf{P}$ (i.e. metalinguistic negation)

or: not [the P is F]; there is no P (i.e. descriptive 'presupposition'cancelling negation)

(14a) and (14b) give the standard Gricean analysis, on which there is no semantic relation of presupposition; the existential implication is derived pragmatically, either as an implicature or as an enrichment at the level of the proposition expressed, a narrowing of the scope of the negation operator. These first two levels have been assumed by the Griceans to capture adequately the two possibilities: the 'presupposition'-cancelling and the 'presupposition'-preserving. However, what is missing here, as Burton-Roberts points out, is any recognition of the marked, nonpreferred, status of the presupposition-cancelling interpretation and the extra effects it seems to achieve in communication. This is reflected in (14c), which involves a second try, a pragmatic reanalysis, prompted by the contradiction arrived at during the first pass shown in (14b). Note that the contradiction here is not the outcome of the linguistic semantics; it has been derived pragmatically and is therefore compatible with the evidence in (13).

This reanalysis may take either of two forms depending on the specifics of context. The move to a metalinguistic interpretation is the more likely option. But there is, in principle, another possibility here, a 'return', as it were, to the descriptive, wide-scope, 'presupposition'-cancelling semantics. Certainly something akin to this latter process occurs in the garden-pathing examples in (15): 
a.I've had breakfast; I had it ten years ago when I

worked a night shift.

b.Edina: Have you caten?

Patsy: No-not since 1973.

(from 'Absolutely Fabulous' BBC2, 9/2/94)

There is, of course, nothing metalinguistic going on here. But a pragmatic reanalysis takes place as a result of the second clause in each case which is at odds with the temporal enrichment made on-line in processing the first clause. The reanalysis is one of undoing or repairing that first pass pragmatic enrichment. There is, then, as far as I can see, nothing inevitable about a metalinguistic analysis of the presupposition-denying cases, contrary to the Burton-Roberts view.

So far, then, there are no tidy generalizations to be made about cases of metalinguistic negation: some, but not others, are rejoinders to previous utterances; some, but not others, are semantic contradictions; some, but not others, of those that are descriptive contradictions are garden-path utterances; some, but not others, of those that are not contradictory are garden-pathers; some, but not others, involve a correction clause which may either precede or follow the negative clause.

There is an interesting subset of cases whose general form has become almost a set formula for achieving rhetorical effects. These have the following properties: (a) the correction clause follows the negative clause; (b) they are standardly logical contradictions; and (c) they standardly create a descriptive garden-path before the metarepresentational interpretation is derived. These examples are highly effective and so memorable, but they do not form a natural class, linguistically or pragmatically. To assume they do has as little validity as assuming that the examples in (15) somehow constitute a natural class of cases. These, too, are just instances of a much more general phenomenon, illustrated by the examples in (10): the process of pragmatic enrichment of linguistically decoded content in deriving the proposition expressed. The examples in (15) happen to have the further property of having been designed, first to mislead and then to correct, for the sake of achieving some special effects.

\section{The essential property: implicit echoic use}

The correct generalization about the metalinguistic cases is that the material in the scope of the negation operator, or some of it at least, is echoically used, in the sense of Sperber \& Wilson (1986), Wilson \& Sperber (1988, 1992). A 
representation is used echoically when it reports what someone else has said or thought and expresses an attitude to it. Typical examples are given in (16):

a.The obnoxious beady-eyed woman is my wife.

b.It's a lovely day for a picnic, indeed.

The speaker of (16a) might be using the definite description truth-conditionally but is even more likely to be attributing it to someone else and expressing an attitude to it, conceivably one of endorsement, but more likely one of dissociation/rejection. This latter possibility contains the crucial ingredients of ironic utterances: the (implicit) attribution of an opinion and the (implicit) expression of an attitude of dissociation from that opinion. Similarly, (16b) might be a description of a state of affairs in the world, but in the appropriate context it might be used echoically to recall an earlier utterance or attribute a thought or opinion to someone, and express one of a range of attitudes to it. When it is a case of echoing an utterance there is a range of properties in addition to semantic or conceptual content that might be the target of the echo: linguistic factors such as phonetic, grammatical or lexical properties, aspects of dialect, register or style, and paralinguistic features such as tone of voice, pitch or other gestures, audible or visible. What all these possible types of echoic use have in common and what they share with a wider class, including cases of mention, quotation and free indirect speech, is that a representation is being used not to represent an object or state of affairs in the world but to represent a representation. In such cases the relationship between representation and that which is being represented is not the familiar truthbased descriptive sort but is one of resemblance (Sperber and Wilson 1986, 226-37; Wilson and Sperber 1988; 136-40).

Consider (17) in which aspects of linguistic form are echoed; that is, 'tom[eiD uz]' is not being used to refer to a particular set of entities in the world but instead represents a particular pronunciation which it closely resembles, and 'get stressed out' is not used here to represent an emotional state of mind but rather to represent a particular idiom which it resembles (and is possibly identical to):
a.Around here we don't eat tom[eiD uz] and we don't get stressed out. (We eat tom[a:t uz] and we get a little tense now and then.)
b.Since when have you been eating tom[eiD uz] and getting stressed out?

The attitude expressed by these cchoic uses is one of rejection. That attitude is made explicit in (17a) by the use of negation and is left implicit in (17b). (17a) is, of course, one of the standard cases of metalinguistic negation. Note that in both of the examples in both (16) and (17) the echoic nature of the representation is left 
implicit. This, I claim, is the crucial property of so-called metalinguistic negations: the representation (or a part of it) falling in the scope of the negation operator is implicitly echoic. Compare this with cases where the echoic nature of the representation is made explicit:

(18) It's not correct to say that you saw two 'mongeese'; you should say 'mongooses'.

(19) It's not eSOTeric; it's esoTERic.

a.Is her dissertation terribly eSOTeric?

b.Is the correct pronunciation eSOTeric or esoTERic?

(example due to Noel Burton-Roberts)

In reply to the question in (b), the speaker of (19) is explicitly quotational, as she obviously is in (18); the referent assigned to 'it' is 'the correct pronunciation'. As a reply to (a), on the other hand, (19) is most probably implicitly echoic, the referent of 'it' being 'her dissertation'; this is one of the typical metalinguistic negation cases. As Sperber \& Wilson (1986) point out with regard to irony, it is precisely the implicit nature of the echoic use which gives these their garden-pathing potential. It is interesting in this regard to look at their comments on example (115a) (their numbering):

(115) a.When all was over and the rival kings were celebrating their victory with Te Deums in the respective camps ...

(Voltaire: Candide)

"In fact (115a), like many of the best examples of irony, is a garden-path utterance, likely to cause the reader momentary processing difficulties later offset by appropriate rewards. One at first reads it as an ordinary assertion, is led to the absurd conclusion that both sides won, and only then reinterprets echoically. By leaving the echo implicit when the addition of some explicit material [as in (115d)] would have immediately put the reader on the right track, the author opens up a whole new line of interpretation....

(115) d.When the battle was over and the rival kings were doing what they described as celebrating their victory with Te Deums in their respective camps ..."

Sperber and Wilson $(1986,242)$

This property of implicit echoic use, then, accounts quite straightforwardly for why it is that these 'metalinguistic' negations lend themselves to effective garden- 
pathing, though this is not, of course, an inevitable feature of either ironical utterances or these echoic negations.

Analysis of the metalinguistic negation cases in terms of echoic use seems to account well also for two of the standard formal diagnostics, noted by Horn (1985, 1989 ) and virtually everyone else who has looked at the phenomenon: the presence of positive polarity items in their scope and the failure of morphological negation to function metalinguistically:
a.Mary is sometimes late.
b.* Mary is ever late.
c.Mary isn't ever late.
d.Mary isn't sometimes late. (She's always late.)

The descriptive negation counterpart of (20a) is (20c), with the negative polarity item 'ever'. The presence of the positive polarity item 'sometimes' in (20d), however, is entirely to be expected once it is recognised that what is going on is the echoing of the affirmative which contains the positive polarity item.

a.She's not happy; she's ecstatic.

b.* She's unhappy; she's ecstatic.

Horn $(1989,392)$ discusses this failure of metalinguistic negation to incorporate morphologically. He finds it understandable because, as he puts it in one of his few allusions to the quotational nature of metalinguistic negation, the negation operator is functioning "on a different level from the rest of the clause". More precisely, the echoed material 'She's happy' is, as it were, within quotation marks and so is sealed off from the negation which lies outside the quote/echo.

\section{The implicit echo of truth-conditional content?}

I have tried to show in the previous section that a general characterization of the class of metalinguistic negations is possible using the concept of implicit echoic use. However, the thought that immediately arises is that on an echoic analysis there is nothing to exclude the truth-conditional content of the material in the scope of negation being echoed (and objected to) and it is not yet clear that we want this possibility.

I have concentrated so far on non-truth-conditional properties, mostly, in fact, on formal linguistic properties, following Horn and others. But the concept of echoic use applies more widely than this; in their work, Sperber and Wilson have 
given many examples where the speaker is not echoing an element of linguistic form but is echoing the content of someone's utterance or indeed is attributing a (possibly unarticulated) thought or opinion to someone. For instance, in the analysis of irony the echoic allusion primarily concerns descriptive content, as in the cases in (16).

Recall that Horn talks of metalinguistic negation as involving an objection to an utterance on any grounds whatever; now, finding the truth-conditional content false is certainly a ground on which one might object to someone's utterance. Is it reasonable, then, to class the examples in (22) together with the standard metalinguistic cases as all instances of implicitly echoic negations?

a.X: Isn't it tiring for you to drive to work?

Y: I don't DRIVE to work; I JOG.

b.X: Oh, you're in a miserable foul mood tonight.

Y: I'm not in a miserable foul mood; I'm a little tired and would like to be left alone.

c.Winning isn't everything; it's the only thing.

d.They're not the best at what they do - they're the only ones who do what they do.

Certainly, Y's utterances in (22a) and (22b) are not contradictory, unlike so many of the standardly cited examples. However, as I've argued above, contradictoriness does not seem to be an essential property of metalinguistic (perhaps more aptly, metarepresentational) use. It is not clear to me whether we would want to say that $\mathrm{Y}$ in each case is objecting to the truth-conditional content of X's utterance or to something more formal like the use of a particular lexical item or phrase, which happens to make a truth-conditional difference. As for (22c) and (22d), they seem to conform to the formula that Horn and Burton-Roberts take to be typical of metalinguistic uses and they have the same sort of rhetorical effectiveness, perhaps involving some kind of garden-path. Again, it is far from clear whether it is truthconditional content or lexis that is being objected to. Arguably, the birthday card example in (3) above involves the echo of descriptive content too, though not the content of an actual previous utterance. Rather, what is echoed there is the general assumption/expectation/hope that a birthday card that one receives will be from an admirer. This loosening of what is echoed from strictly formal linguistic properties of an utterance and, finally, from any actual previous utterance at all, is just as one would expect from the Sperber and Wilson account.

The reluctance to include truth-conditional content as a possible ground for objecting to someone's (actual or potential) utterance is that such echoic cases would seem then to be effectively indistinguishable from standard descriptive 
negations, which, of course, operate over truth-conditional content. However, there is an interesting parallel that can be drawn here, with another sort of echoic case, which is often virtually indistinguishable from its descriptive counterpart. This is the case where an attitude of endorsement is expressed towards implicitly echoed material. Sperber and Wilson (1986) discuss the following examples (their numbering):

(111) a.Peter: It's a lovely day for a picnic.

[They go for a picnic and the sun shines.]

b.Mary (happily): It's a lovely day for a picnic, indeed.

(112) a.Peter: It's a lovely day for a picnic.

[They go for a picnic and it rains.]

b.Mary (sarcastically): It's a lovely day for a picnic, indeed.

"In both (111b) and (112b) there is an echoic allusion to be picked up. In the circumstance described, it is clear that the speaker of $(11 \mathrm{lb})$ endorses the opinion echoed, whereas the speaker of $(112 b)$ rejects it with scorn. These utterances are interpreted on exactly similar patterns; the only difference is in the attitudes they express. (111b) has not been thought by rhetoricians to be worthy of special attention; (112b) is, of course, a case of verbal irony."

Sperber \& Wilson $(1986,239)$.

Unusually, it is the endorsement case (111b) that I am interested in here. Let's compare it (repeated in (23b)) with its non-echoic (i.e. descriptive) counterpart given in (23a):

a. It's a lovely day for a picnic.

b. It IS a lovely day for a picnic (indeed).

They look and sound pretty much the same, though, as I've attempted to indicate, there may be some superficial clues towards the echoic analysis, such as a particular accent pattern, and (perhaps) the use of the inessential 'indeed'. There will, presumably, be a difference in the communicative intention of the speaker in each case and slight differences in the effects achieved, or in the way in which they are achicved. The effects in the echoic case may well be focused on giving Peter a pat on the back for having got it right, for having exercised such good judgement, effects which might be less prominent in the case of the descriptive assertion that happens to be in agreement with Peter's earlier assertion. However, the difference 
between them will, in many instances, be pretty negligible and it won't matter much which of the two possibilities the hearer derives.

This lack of a particularly sharp interpretive difference in the case of some endorsing echoes and their descriptive counterparts does not lead us to the conclusion that the distinction doesn't exist; that is, to the conclusion that echoic allusion with an attitude of corroboration is not a real possibility. What I am suggesting is that the same goes for cases of echoing the truth-conditional content of the representation in the scope of negation and their descriptive, non-echoic, counterparts. So B's response to A in (24) might be a case of echoic negation, the assertion that 'she's happy' being attributed to A, or it could be an ordinary descriptive use, a counter-assertion to $\mathrm{A}$ 's assertion:

A:Mary seems happy these days.

$\mathrm{B}$ :She isn't HAPPY; she just puts on a brave face.

In the absence of any more specific context there is just no way of knowing. In context, the two possibilities may differ slightly in the effects they achieve or in the way those effects are achieved, the force of the dissociative attitude being stronger in the echoic case than in the descriptive case, though very often the upshot will be much the same.

A small piece of evidence in favour of maintaining the distinction, despite its sometimes negligible effect on interpretation, comes from a consideration of the formal diagnostics of metalinguistic use, especially the presence of positive polarity items:

A:Mary is sometimes late.

B1:She isn't ever late; she's always punctual.

B2:She isn't sometimes late; she's always punctual.

The negative polarity item 'ever' in B1 would indicate descriptive use of the material in the scope of negation, while the positive polarity item 'sometimes' in B2 indicates that A's utterance is being echoed, and, as the follow-up clause shows, it is the truth-conditional content of the utterance that is being objected to.

It seems then that a properly general account of cases of marked negation can be given in terms of implicit echoic use, an account which includes the rhetorically effective formulas that Horn and others have concentrated on but which is far from exhausted by them[FN7].

Finally in this regard, I should address the view (which I do not share) that all utterances of negative sentences are echoic. Throughout the long history of treatments of negation (see Horn 1989) the consensus has been that there is a 
perfectly general asymmetry between positives and their corresponding negatives: while utterances of positives are readily interpreted as descriptive assertions without requiring any particular type of contextual assumption, negative utterances are felt to require or suggest a background context containing the corresponding positive proposition. It seems to be a short hop from this observation to the view that all negative utterances are echoic, in the rather broad relevance-theoretic sense of echoic that I am employing. If this were right my approach would be found wanting in that it would appear to collapse all negations into a single category (of echoic use) while the one thing everyone seems agreed on is that there are two distinct types, those that have been generally assumed to be descriptive/truth-conditional and those that have been called metalinguistic.

I believe that the distinction between descriptive negations and echoic negations should be maintained. Consider the following scenario: Bill knows that Sue is firmly and miserably of the opinion that she hasn't got the job she applied for; she has made this negative assertion repeatedly. Bill happens to learn the happier truth and announces to her 'You got the job'. There is no inclination to say that Bill's positive utterance is echoic of Sue's (mutually known) negative thought or assertion, though it is certainly that which Bill is addressing and contradicting. In relevance-theoretic terms the main contextual effect of his utterance is one of contradicting and climinating a particular assumption (and its implications). The same goes, I contend, for the opposite setup - where Sue is sure she got the job and Bill tells her that she didn't get it -and for a great many negative utterances: they contradict, and may eliminate, positive contextual assumptions, without (necessarily) being echoic of those positive assumptions. I am not disputing a positive/negative asymmetry; it seems uncontroversial that a negative has this contradiction/denial function far more often than a positive does and it would be nice to have a fully satisfactory account of why this should be so (Horn 1989 , chapter 3 , considers some possible explanations). The only point I want to make is that it does not follow from this undoubted asymmetry that all negative utterances are cases of echoic use.

Furthermore, there is a range of structures in which negatives may appear and for which there is no inclination to say echoic use must be involved:
a. People who don't want to stay to the end should sit by the door.
b. If we don't leave soon we'll miss the bus.
c. Whether or not I get the job I'll stay in England.

On the basis of this sort of evidence we certainly couldn't say that a negative clause inevitably involves echoic use. 
Nevertheless, my account may give some people the uneasy feeling that an intuitively clear distinction is being blurred. This is not because all negative utterances are echoic and it is not, I hope, because I am wrong to postulate a broad class of echoic instances which includes the blatantly formal (metalinguistic) cases together with cases where truth-conditional content is echoed. The original descriptive distinction between descriptive and metalinguistic negation was a response to the quite crisp intuitions we have about cases such as (1a) and (1b), repeated here:

We didn't see the hippopotamuses.

a. We saw the rhinoceroses.

b.We saw the hippopotami.

As is standard with such theoretical distinctions (cf. grammatical/ungrammatical; saying/implicating) one starts from the clear cases. As we develop the distinction into something more principled and explanatory, as I've tried to do here, intuitions may get nudged a little and some of the data may begin to look a bit different. Any linguistic expression can be used echoically and whether, in any given instance, an echoic or descriptive interpretation is intended and recovered is a matter of context and pragmatic inference. In the case of (1b) an echoic interpretation is virtually certain given the contradictoriness of a descriptive interpretation and the single salient formal difference between the two clauses. The cases where it is truthconditional content which is the focus of the negation may not be obviously resolvable as descriptive or echoic out of context. Some of them, however, lend themselves more readily than others to an echoic interpretation, such as the presupposition-denying examples; as the discussion in section 3 indicates, in the absence of contextual specifics the first relevant interpretation to be recovered tends to be the echoic one. For cases such as (la) the out-of-context default interpretation appears to be the descriptive interpretation; in the absence of any indications to the contrary this generally takes less effort to access than the echoic interpretation and there is no reason to suppose it wouldn't have an adequate range of contextual effects.

\section{Last considerations}

Let us return to the issue of the alleged ambiguity of negation, whether semantic or pragmatic. On the account I have just proposed there is no reason to suppose the negation operator is either semantically ambiguous or, if the term makes sense at all, pragmatically ambiguous. There is a 'duality of use' involved in the 
metalinguistic examples, though it is not an ambiguity in the lexical item 'not'. It lies rather with the two ways in which material falling within the scope of 'not' can be used: either to represent a state of affairs in the world (i.e. truth-based representation) or to represent another representation (i.e. resemblance-based representation, which includes echoic use). This particular duality of use is not in any way peculiar to negative utterances but is a thoroughly pervasive feature of language use. I am moved by these observations to repeat my assertion (Carston 1985) that the negation operator itself is, in all instances, just the standard truthfunctional operator. This view has, however, met with considerable scepticism; for instance:

"We are now back to the ultimately incoherent view that negation is invariably a truth function - even when it takes as an argument the 'echoic use of language'. If there is no category mistake here, there is at the very least a good deal of explaining to do, since Carston is forced by her neomonoguism to propositionalize every target of metalinguistic negation, from grammatical usage to phonology, from register to musical technique. ... when we bear in mind what a truth function must be a function of, we recognize the implausibility in the view that negation is invariably truth-functional."

Horn $(1989,434)$, endorsed by Foolen $(1991,228)$ and repeated in Horn (1992).

So the claim that the negation operator is truth-functional in all these cases, clearly, calls for substantiation. Ideally, it would be addressed in tandem with the issue of what proposition is expressed and recovered in these echoic cases. This latter matter concerns how (if at all) the implicitly echoed/quoted material within the negation is pragmatically unpacked into an explicit representation by the hearer/reader. I won't give a full account here (I don't have one yet) but there are some considerations which, I think, should serve to temper statements about category mistakes and extreme implausibility.

First, consider the following conjunctions:

$$
\text { a.Mary says [p teit u] and John says [p ta:t u]. }
$$

b.You like po-tay-to and I like po-tah-to.

(from Gershwin: Let's Call the Whole Thing Off)

Now, surely, however we might finally decide to represent the proposition expressed by (27a) we have no problem in saying what its truth-conditional content is; it is true if and only if Mary pronounces the word in question in a particular way and John pronounces it in another particular way. I don't think there is any 
temptation here to say that the conjunction operator is not its standard truthfunctional self even though parts of the representation falling in its scope are phonetic and quotational. Of course, this metarepresentational use is explicitly signalled in (27a) by use of the verb 'say'. In (27b), on the other hand, there is no linguistic encoding of the fact that what are being contrasted are two different pronunciations of a single word rather than the denotations of two different words[FN8]; that is, its metarepresentational nature is implicit. I see no reason to suppose that this thereby renders the conjunction operator non-truth-functional, although we may be unclear about how to represent the proposition(s) expressed by the speaker and recovered by the hearer.

Naturally, similar considerations can be brought to bear on cases of metalinguistic disjunction (the disjunction operator retaining its truth-functional character) and, more to the point here, on metalinguistic negation. Recall examples (18) and (19), the latter repeated here:

It's not eSOTeric; it's esoTERic.

a.Is her dissertation terribly eSOTeric?

b.Is the correct pronunciation 'eSOTeric'?

c.Her dissertation is not eSOTeric; it's esoTERic.

d. The correct pronunciation of the word is not

'esOTeric'; it's 'esoTERic'.

Assuming the two different possible assignments of reference to 'it' given in (c) and (d), we get the one interpretation which involves an implicit echo (so-called metalinguistic negation) and the other where it is made explicit that a stretch of phonetic representation falls in the scope of negation. There seems to be no difficulty in giving the truth-conditions of the latter and in maintaining the truthfunctionality of the negation operator: the first clause of (d) is true if and only if it is false that the word in question is correctly pronounced [eSOTeric]. So, again, the question arises whether the 'meaning' of the negation operator is altered by the fact that the metarepresentational nature of some material in its scope is not explicitly signalled, as in (c). This implicitness does entail that there is some considerable pragmatic work for the hearer to do, since anyone who has fully understood the response with reference assigned as in (c) will have recovered, among other things, the information that one possible pronunciation of the word 'esoteric' is being rejected and another is being endorsed. This inference may constitute a pragmatic contribution to the proposition expressed by the utterance[FN9], giving something like the representation in (28), or it may be an implicature. 
(28) Not [the correct pronunciation of the word $\mathrm{x}$ in "her dissertation is $\mathrm{x}$ " is "eSOTeric"]; the correct pronunciation of the word $\mathrm{x}$ in "her dissertation is $\mathrm{x}$ " is "esoTERic"[FN10].

Either way, there seems to be no reason to suppose that the negation operator somehow loses its truth-functionality and acquires a new meaning such as 'I object to $\mathrm{U}$ ' or ' $\mathrm{U}$ is unassertable'.

This overly brief but, I hope, suggestive discussion points to where the real problem lies, which is with the great need for some deeper understanding of where the metarepresentational use (of which echoic use is a subtype) of natural language comes from. Should it be thought of as a semantic ambiguity, or a pragmatic ambiguity, or something else altogether, a reflex in public language of a fundamental cognitive capacity perhaps? Is it a feature of the language faculty and, if so, does that entail that every sentence has various semantic representations with, as it were, quotation marks around certain constituents? If it is not a part of the grammar then how does it arise in interpretation? These questions are raised by the analysis of metalinguistic negation in terms of echoic use, though they are obviously not peculiar to it, since they arise elsewhere too, as a result of the very widespread occurrence of the metarepresentational use of language. I don't suppose they are going to receive any swift or easy answers.

\section{Footnotes}

* This is a revised and extended version of a paper that appeared, under the same name, in 1994, in UCL Working Papers in Linguistics 6, 321-349. I am very grateful to Noel Burton-Roberts, Eun-Ju Noh and Deirdre Wilson for many interesting conversations on the topic of this paper, and to Larry Horn for his encouraging response to it. Thanks also to the students who took my course 'Issues in Pragmatics' in the spring term 1994 and contributed to some very stimulating back-up classes on negation.

1. The origin of the term 'metalinguistic negation' is usually traced to Ducrot (1972).

2. The way this is often expressed is in terms of an objection to the (generalised) scalar implicature carried by the use of the word 'or', that 'not (P and Q)' (see Horn $1989,6.3)$. 
3. In Gricean terms this is a conventional implicature: 'deprive' and 'spare' are taken to be truth-conditionally equivalent but to carry a semantic difference concerning the (un)desirability of their object.

4. Burton-Roberts (1989b) is led to this via a conjunction of convictions: (a) there are semantic presuppositions; (b) all presupposition-cancelling cases are metalinguistic negations; (c) all metalinguistic negations are literal contradictions; (d) the first interpretation of an utterance that a hearer accesses is its descriptive truth-conditional one. I examine this wider programme in more detail elsewhere (Carston forthcoming).

5. The enrichment of conjunction has been extensively discussed and motivated within Relevance Theory (Blakemore 1987, Carston 1988, Wilson \& Sperber 1993); the shift from a scalar implicature treatment of cardinal number cases to a pragmatic enrichment account has been discussed within Relevance Theory (Kempson 1986, Carston 1988, 1990) and by Horn (1992).

6. Burton-Roberts' account of negation in a presuppositional semantics is, in fact, more subtle than this, though this does not change the point I am making here. I address his account (in its full subtlety) in greater detail in another paper (Carston forthcoming).

7. Van der Sandt (1991)'s account of metalinguistic negation in terms of echoic denial appears to be similar in spirit to the account proposed here. However, his echo operator requires a previous utterance to operate over and can take within its scope only the informative content of the utterance, i.e. propositional content including presuppositions, implicatures and connotations. So he gives no account of the cases which involve echoes of formal linguistic properties and makes the false prediction that metalinguistic negation may target particularized implicatures.

8. It should be noted that an alternative analysis of this sort of example and of some of the negation cases has been pointed out by McCawley (1991, 190): a speaker who presents these two pronunciations in this sort of contrastive way may be treating them as if they are different words with distinct denotations and this pretence may be what gives rise to their special effects.

9. This would then be just one of the many cases of pragmatic enrichment of the encoded logical from of the utterance required in order to arrive at the proposition the speaker intended to express (the truth-conditional content of the utterance). It is 
now fairly widely, though by no means universally, acknowledged that linguistic content radically underdetermines truth-conditional content.

10. A similar sort of representation has been proposed already, by Seuren (1990, 444) but for him it is wholly a matter of linguistic semantics: he takes (28) (or something along these lines) to be a semantic deep structure which undergoes certain movement and deletion rules to give the surface form in $(19 \mathrm{c})$. On the sort of account $\mathrm{I}$ favour it would be the outcome of pragmatic development of the decoded logical form of (19).

\section{References}

Blakemore, Diane, 1987. Semantic constraints on relevance, Oxford: Blackwell.

Burton-Roberts, Noel, 1989a. On Horn's dilemma: Presupposition and negation. Journal of Linguistics 25: 95-125.

Burton-Roberts, Noel, 1989b. The limits to debate. Cambridge: Cambridge University Press.

Carston, Robyn, 1985. A reanalysis of some 'quantity implicatures'. Unpublished, University College London.

Carston, Robyn, 1988. Implicature, explicature and truth-theoretic semantics. In: R. Kempson, ed., Mental representations: The interface between language and reality, 155-181. Cambridge: Cambridge University Press. Reprinted in: S. Davis, ed., 1991, Pragmatics: A reader, 33-51. New York/Oxford: Oxford University Press.

Carston, Robyn, 1990. Quantity maxims and generalised implicature. UCL Working Papers in Linguistics 2: 1-31.

Carston, Robyn, forthcoming. Metalinguistic negation, 'presupposition' and the semantics/pragmatics distinction.

Chapman, Siobhan, 1993. Metalinguistic negation, sentences and utterances. Newcastle and Durham Working Papers in Linguistics 1, 74-94.

Cormack, Annabel, 1980. Negation, ambiguity and logical form. Unpublished, University College London.

Ducrot, Oswald, 1972. Dire et ne pas dire. Paris: Hermann.

Foolen, Ad, 1991. Metalinguistic negation and pragmatic ambiguity: Some comments on a proposal by Laurence Horn. Pragmatics 1, 217-237.

Horn, Laurence, 1985. Metalinguistic negation and pragmatic ambiguity. Language 61: 121-174.

Horn, Laurence, 1989. A natural history of negation. Chicago: University of Chicago Press. 
Horn, Laurence, 1990. Showdown at truth-value gap: Burton-Roberts on presupposition. Journal of Linguistics 25: 483-503.

Horn, Laurence, 1992. The said and the unsaid. Ohio State University Working Papers in Linguistics (SALT II Proceedings), 40. Ohio State University.

Kempson, Ruth, 1986. Ambiguity and the semantics-pragmatics distinction. In: C. Travis, ed., Meaning and interpretation, 77-104. Oxford: Blackwell.

McCawley, James, 1991. Contrastive negation and metalinguistic negation. Chicago Linguistic Society 27: The Parasession on Negation, 189-206.

van der Sandt, Rob, 1991. Denial. Chicago Linguistic Society 27: The Parasession on Negation, 331-344.

Seuren, Pieter, 1990. Burton-Roberts on presupposition and negation. Journal of Linguistics 26: 425-453.

Sperber, Dan and Deirdre Wilson, 1986. Relevance: Communication and cognition. Oxford: Blackwell.

Wilson, Deirdre and Dan Sperber, 1988. Representation and relevance. In: R. Kempson, ed., Mental representations: The interface between language and reality, 133-153. Cambridge: Cambridge University Press.

Wilson, Deirdre and Dan Sperber, 1992. On verbal irony. Lingua 87: 53-76.

Wilson, Deirdre and Dan Sperber, 1993. Pragmatics and time. UCL Working Papers in Linguistics 5: 277-298. 